\title{
EVALUASI PROGRAM PENGENDALIAN TUBERCULOSIS DI WILAYAH KERJA PUSKESMAS
}

\author{
(Studi di Kota Ambon)
}

\author{
Lodri Parera' $^{1)}$, Suharyo Hadisaputro ${ }^{2)}$, Djoko Tri Hadi Lukmono ${ }^{3)}$ \\ 1),2),3) Program Studi Magister Epidemiologi, Sekolah Pascasarjana, Universitas Diponegoro \\ E-mail : lodri.parera@gmail.com
}

\begin{abstract}
The TB control program has been carried out at each publich bealth centers in Ambon city. But the decrease in the number of new and old cases is not sufficiently accelerated according to the target, there are still bigh $T B$ cases and there are also differences or disparities in the number of case detection rates between puskesmas and case detection The highest rate is among the puskesmas with the lowest CDR. This study aims to control tuberculosis in the working area of the health center. The type of research used in this research is descriptive analytic research using an observational approach supported by qualitative research. The sample is the program and also the TB laboratory staff at the Ambon City publich health centers, the bolder of 44 respondents. Descriptive data analysis with the results described in narrative form then compared the level of case data. The results showed that the case finding program and treatment of TB patients as well as health promotion were carried out by 100\% of the respondents. The TB sputum examination program was well implemented by 18 (81.8\%) TB laboratory staff respondents. This is related to suspects that do not return the sputum pot. Program TB officers or laboratory workers have multiple jobs, as well as demographic conditions that are far away and difficult to reach by vehicle. Selection of places for TB promotion activities and health centers that are far from where the community lives. Laboratory conditions that should be separate and small for TB. Laboratory staff receive poor quality sputum provided by program holders. The TB control program is carried out and has been running well, but there are several conveniences that the sputum pot cannot return, demographics, treatment at other health facilities, inadequate space and not good enough sputum quality.
\end{abstract}

Keywords: Program evaluation; tuberculosis. 


\begin{abstract}
ABSTRAK
Program pengendalian TB Telah dilakukan pada tiap-tiap puskesmas di kota Ambon. Tetapi penurunan Angka kasus baru dan lama tidak cukup mengalami percepatan sesuai dengan yang ditargetkan, masih saja ada kasus TB yang tinggi dan juga terdapat beda atau disparitas angka Case Detection Rate antara puskesmas dengan Case Detection Rate tertinggi Terhadap puskesmas dengan CDR terendah. Penelitian ini bertujuan mengevaluasi pelaksanaan program pengendalian tuberculosis terhadap Case Detection Rate di wilayah kerja puskesmas. Jenis penelitian yang dipakai dalam penelitian ini ialah penelitian deskriptif analitik menggunakan pendekatan observasional yang ditunjang dengan penelitiaan kualitatif. Sampel Merupakan pemegang program dan juga petugas laboratorium TB di Puskesmas Kota Ambon, seluruhnya berjumlah 44 reponden. Analisis data secara deskriptif dengan hasilnya yang diurai dalam bentuk narasi kemudian dibandingkan case datection rate. Hasil penelitian terlihat bahwa Program penemuan kasus dan pengobatan pasien TB serta promosi kesehatan yang dilakukan 100\% oleh responden. Program pemeriksaan sputum TB dilaksnakan secara baik oleh $18(81,8 \%)$ responden petugas laboratorium TB. Hal ini terkait suspek yang tidak mengembalikan pot dahak. Petugas program TB maupun petugas laboratorium mempunyai kerja rangkap, serta kondisi demografi yang jauh dan sulit di jangkau dengan kendaraan. Pemilihan tempat kegiatatan promosis TB dan puskesmas yang jauh dari tempat tinggal masyarakat. kondisi laboratorium yang harusnya terpisah dan kecil untuk TB. petugas laboratorium mendapat sputum kualitasnya kurang baik yang diberikan oleh petugas pemegang program. Program pengendalian TB dilakukan dan sudah berjalan dengan baik namun terdapat beberapa kendala yakni tidak dikembalikannya pot dahak, demografi, pengobatan di fasilitas kesehatan yang lain, kurang memadainya ruangan laboratorium dan kualitas sputum yang tidak cukup baik.
\end{abstract}

Kata Kunci :Evaluasi program; tuberkulosis.

\section{PENDAHULUAN}

TBC merupakan penyakit menular yang disebabkan oleh bakteri Mycobacterium tuberculosis. TBC dapat menyerang organ lain tetapi biasanya menyerang paru (TB ekstrapulmoner). Menyebarnya penyakit ini pada saat individu maupun orang yang sakit TB paru menghembuskan bakteri ke udara, contohnya dengan batuk (WHO, 2016).TB ialah salah satu penyakit yang menular yang kasusnya hingga sekaranga ini masih tinggi di masyarakat. TB mengancam keselamatan jiwa serta sangat berdampak luas bagi kualitas hidup dan ekonomi. Seluruh dunia pada Tahun 2015, diperkirakan 10,4 juta kasus baru TB (kejadian). 1,4 juta kematian akibat TB pada tahun 2015, serta adanya tmbahan 0,4 juta kematian yang disebabkan TB di antara orang atau individu yang hidup dengan HIV.3. TB tetap sebagai salah satu dari 10 besar penyebab kematian di seluruh dunia pada tahun 2015, Meskipun jumlah kematian TB mengalami penurunan 22\% antara pada tahun 2000 sampai 2015, (WHO, 
2016).Indonesia jumlah kasus baru tuberkulosis paru BTA yang positif untuk tahun 2016 sebanyak 156.723 sedangkan cakupan penemuan kasus penyakit Tuberkuslosis 454.851. Provinsi Maluku terdapat 1.508 kasus baru BTA yang positif sedangkan seluruh kasus penyakit Tuberkulosis sebanyak 2.961 kasus (Kemenkes RI, 2017).

Di Indonesia upaya pengendalian TB berlangsung sudah sejak sebelum kemerdekan. Setelah perang dunia II, melalui 20 balai pengobatan dan juga15 sanatorium yang pada umumnya berada di pulau Jawa yang dilakukan secara terbatas. Melindungi kesehatan masyarakat dari penularan TB agar tidak terjadi kesakitan, kematian hingga kecacatan merupakan tujuan program pengendalian tuberkulois. Dalam menilai keberhasilan serta kemajuan program digunakan berbagai indikator yakni indikator dampak,utama dan operasional. Indikator utama dipakai menilai pencapaian strategi nasional penanggulangan penyakit TB di tingkat Kabupaten/Kota, Provinsi, dan Pusat. Indikator itu salah satunya ialah Cakupan pengobatan semua kasus TB (case detection rate/CDR) yang diobati. Jumlah semua kasus TB yang diobati dan juga dilaporkan di antara perkiraan jumlah semua kasus TB (insiden) ialah CDR. Seberapa sedikit banyaknya kasus TB yang telah terjangkau oleh program merupakan gambaran CDR. Keberhasilan dan kesuksesan penanggulangan TB ialah menemukan penderita TB dan juga mengobati penderita TB sampai sembuh.(Kemenkes RI, 2017). WHO menetapkan target global Case Detection Rate 70\% (Kemenkes RI, 2011).

Berbagai program maupun kegiatan pengendalian di Kota Ambon yang dijalankan meliputi penemuan kasus, pengobatan pasien, dan promkes serta pemeriksaan sputum. Evaluasi adalah suatu upaya maupun usaha pengawasan dalam rangka menilai juga mengukur keberhasilan serta efektivitas progam sebuah institusi dalam rangka pencapaian tujuan organisasi. Dalam hal ini evaluasi berperan sangat penting sebagai alat monitoring program maupun kegiatan. Selain itu juga evaluasi sebagai instrumen perencanaan, mengidentifikasi faktor penyebab dan mengidentifikasi disparitas yang terjadi antara harapan dan juga realisasi pencapaian kegiatan atau program, serta memberikan prioritas, alternatif pemecahan masalah, sebagai upaya menjaga dan memperbaiki kualitas pencapaian kinerja suatu organisasi. (Dwijowijoto, 2003). 
Penelitiandi Surakarta oleh Firdaufan dkk pada tahun 2009 menyatakan terdapat disparitas atau beda dalam pencapaian target program pengendalian $\mathrm{TB}$ di kabupaten atau kota kemudian tingkat kecamatan. Ada beberapa kabupaten maupun kecamatan masih belum mencapai tingkat hasil kuantitatif dan kualitatif yang diinginkan atau yang diharapkan (Firdaufan Firdaufan., Santoso., Hartanto R., Hendratno., Sumardiyono \& Syahril M, 2009). Penelitian Noveyani pada tahun 2014 di Surabaya menerangkan penjaringan suspek hampir semuanya (87,5\%), masih ada juga pasien yang tidak mempunyai PMO. Semua (100\%) pasien pernah lupa menelan obat anti tuberkulosis yang diberikan. Penyuluhan yang rutin oleh petugas di puskesmas merupakan suatu faktor pendorong. Faktor yang menghambat yaitu jarak ke puskesmas sebahagian besar $(65,6 \%)$ pasien yakni $>1 \mathrm{~km}$. Pencatatan maupun pelaporan menggunakan atau memakain sistem elektronik dan kemudian dilaporkan secara online berakibat terhadap capaian indikator program (Noveyani, 2014).

Dari 11 kabupaten/kota yang berada di wilayah kerja Dinas Kesehatan Provinsi
Maluku, Kota Ambon diperoleh kasus BTA yang positif 364 dan juga 1.316 kasus TB adalah yang tertinggi dengan CDR 63.89\%. Case Detection Rate tertinggi terdapat pada puskesmas yang memiliki CDR sebesar 60,7\% yaitu puskesma Waehaong,sedangkan puskesmas dengan cakupan pengobatan semua kasus TB yang diobati terendah ada pada puskesmas yang memiliki CDR sebesar 5\% yakni Puskesmas Urimessing. (Dinkes Kota Ambon, 2016). Kota Ambon Belum berhasil mencapai standar indikator Case Detection Rate pada tahun 2017 salah satu penyebabnya ialah pelaksanaan kegiatan/program pengendalian TB yang berlangsung tidak baik maupun tidak optimal. Kegiatan yang hanya berorientasi pada pencapaian target dan bukan pada kualitasnya dalam hal ini pelaksanaan program yang belum sesuai standar merupakan salah satu penyebab Manajemen program pengendalian tuberkulosis di Kota Ambon masih mengalami kendala. Laporan kegiatan program pengendalian TB memperlihatkan sumberdaya kegiatan program seperti tenaga, dana dan juga fasilitas yang telah tersedia secara lengkap tetapi indikator keberhasilan program masih belum juga mencapai target dalam hal ini CDR yang belum mencapai 70\% \% (Dinkes Kota Ambon, 2016). 
Penelitian ini bertujuan Mengevaluasi program pengendalian tuberculosis dengan capaian indikator program di wilayah kerja puskesmas.

\section{METODE}

Jenis penelitian yang dipakai dalam penelitian ini ialah penelitian deskriptif menggunakan pendekatan observasional yang ditunjang dengan penelitiaan kualitatif karena peneliti hanya melakukan pengumpulan data dan pengolahan data tanpa ada intervensi atau perlakuan kepada populasi (Murti, 2010). Studi kualitatif dilakukan dengan cara indepth interview demi memperkuat hasil penelitian (Saryono \& Anggraeni, 2013). Populasi penelitian di dalam penelitian ini yaitu petugas yang terdiri dari 22 petugas pemegang program, dan 22 petugas laboratorium yang tersebar di 22 Puskesmas wilayah Kota Ambon. Teknik pengambilan sampel dalam penelitian ini dilakukan dengan exchaustive sampling yaitu setiap anggota atau unit dari populasi dijadikan sebagai sampel penelitian (Murti, 2010). Sampel yang diambil adalah seluruh petugas pemegang program Tuberkulosis dan petugas laboratorium tuberkulosis di Puskesmas Kota Ambon. variabel terikat pada penelitian ini ialah CDR
Variabel independen meliputi program penemuan kasus TB, pengobatan pasien TB, dan promosi kesehatan TB serta pemeriksaan sputum. Data penelitian terdiri dari data primer yang diperoleh dengan melakukan wawancara dan data sekunder yang diperoleh dari Dinas Kesehatan Kota Ambon. Data primer yaitu berupa hasil dari, wawancara dan jawaban kuesioner melalui: Wawancara mendalam (indepth interview) dengan menggunakan panduan wawancara berstruktur yakni mendapat penjelasan dan keterangan untuk tujuan penelitian dengan menggunakan cara tanya jawab sambil bertatap muka antara pewawancara dengan subjek penelitian serta informan. Analisis data dilakukan secara deskriptif dengan hasil analisis diurai dalam bentuk narasi dan kemudian dibandingkan dengan Case Detection Rate. Penelitian ini sudah ditinjau dan mendapat persetujuan dari Komite Etik Penelitian Kesehatan (KEPK) Fakultas Kedokteran, Universitas Diponegoro dan juga Rumah Sakit dr. Kariadi Semarang. Ethical clearance nomor 619/EC/FKRSDK/XI/ 2018.

\section{HASIL}

Tabel 1. Distribusi Case Detection Rate Puskesmas di Kota Ambon tahun 2017

\begin{tabular}{cc}
\hline Puskesmas & CDR (\%) \\
\hline PKM Latuhalat & 9,8 \\
\hline
\end{tabular}




\begin{tabular}{lc}
\hline PKM Amahusu & 8,5 \\
PKM Air Salobar & 22 \\
PKM Benteng & 36,4 \\
PKM Waehaong & 60,7 \\
PKM Urimessing & 5 \\
PKM Ch.M.Tiahahu & 47,7 \\
PKM Kayu Putih & 34 \\
PKM Belakang Soya & 24,2 \\
PKM Karang Panjang & 13,8 \\
PKM Waihoka & 32 \\
PKM Rijali & 36,3 \\
PKM Air Besar & 40,3 \\
PKM Hative Kecil & 41 \\
PKM Halong & 37 \\
PKM Lateri & 39,6 \\
PKM Passo & 40,1 \\
PKM Nania & 31,2 \\
\hline
\end{tabular}

\begin{tabular}{lc}
\hline PKM Poka & 36,9 \\
PKM Tawiri & 19,8 \\
PKM Hutumury & 11 \\
PKM Kilang & 18,4 \\
\hline Tabel 1 dapat dilihat $\quad$ bahwaseluruh \\
puskesmas di kota Ambon tidak \\
mencapai standar CDR. Capaian CDR \\
tertinggi puskesmas Waehaong dengan \\
CDR 60,7 \%, sedangkan Puskesmas \\
Urimessing merupakan puskesmas \\
dengan capaian CDR terendah dengan \\
presentase 5\%.
\end{tabular}

Tabel 2. Distribusi responden menurut umur,jenis kelamin, pendidikan dan lama kerja

\begin{tabular}{|c|c|c|c|c|c|}
\hline \multirow{2}{*}{$\begin{array}{l}\text { Variabel } \\
\text { Umur }\end{array}$} & \multirow[t]{2}{*}{ Kategori } & \multicolumn{2}{|c|}{ Pemegang program } & \multicolumn{2}{|c|}{ Petugas Lab } \\
\hline & & $\mathrm{n}$ & $\%$ & $\mathrm{n}$ & $\%$ \\
\hline & $>35$ & 6 & 27,3 & 17 & 77.3 \\
\hline & $\leq 35$ & 16 & 72,7 & 5 & 22,7 \\
\hline \multirow[t]{2}{*}{ Jenis Kelamin } & Pria & 2 & 9,1 & 2 & 9,1 \\
\hline & wanita & 20 & 90,9 & 20 & 90,9 \\
\hline \multirow[t]{4}{*}{ Pendidikan } & SMA/SMK & 3 & 13,6 & 1 & 4,5 \\
\hline & DIII Non Analis Kesehatan & 8 & 36,4 & 7 & 31,8 \\
\hline & DIII Analis Kesehatan & 4 & 18,2 & 13 & 59,1 \\
\hline & $\mathrm{S} 1$ & 7 & 31,8 & 1 & 4,5 \\
\hline \multirow[t]{2}{*}{ Lama kerja } & & 11 & 50 & 13 & 59,1 \\
\hline & $\begin{array}{l}<5 \text { tahun } \\
\geq 5 \text { tahun }\end{array}$ & 11 & 50 & 9 & 40,9 \\
\hline
\end{tabular}

Tabel 2 menunjukan bahwa jumlah responden pemegang program $\mathrm{TB}$ terbanyak pada kelompok umur $\leq 35$ tahun sebanyak 16 orang $(72,7 \%)$, sedangkan pada kelompok umur $>35$ tahun sebanyak 6 orang $(27,3)$. Jumlah responden petugas laboratorium terbanyak pada kelompok umur $>35$ tahun sebanyak 17 orang (77,3\%), sedangkan pada kelompok umur $\leq 35$ tahun sebanyak 6 orang (22,3).sebanyak $20 \quad(90,9 \%)$ responden pemegang program TB berjenis kelamin wanita, sedangkan responden pemgang program TB yang berjenis kelamin pria sebanyak 2 $(9,1 \%)$. sebanyak $20(90,9 \%)$ responden petugas laboratorium berjenis kelamin wanita, sedangkan responden petugas laboratorium yang berjenis kelamin pria sebanyak $2(9,1 \%)$. tingkat pendidikan responden pemegang program $\mathrm{TB}$ terbanyak pada DIII non Analis Kesehatan sebanyak 8 orang $(36,4 \%)$, sedangkan yang sedikit terdapat pada responden yang tingkat pendidikan SMA/SMK sebanyak 3 orang (13,6\%). 
Tingkat pendidikan responden petugas laboratorium terbanyak pada DIII Analis Kesehatan sebanyak 13 orang (59,1\%), sedangkan yang sedikit terdapat pada responden yang tingkat pendidikan S1 sebanyak 1 orang (4,5\%).sebanyak 11 (50\%) responden pemegang program TB memiliki lama kerja $<5$ tahun, sedangkan responden pemgang program TB yang memiliki lama kerja $\geq 5$ tahun sebanyak $11(50 \%) . S e b a n y a k ~ 13(59,1 \%)$ responden pemegang program TB memiliki lama kerja $<5$ tahun sedangkan responden pemegang program TB yang memiliki lama kerja $\geq 5$ tahun sebanyak 9 orang $(40,9 \%)$.

Tabel 3. Distribusi Responden Laboratorium Menurut Program

\begin{tabular}{llll}
\hline \multicolumn{1}{c}{ Variabel } & Kategori & \multicolumn{1}{c}{$\mathbf{n}$} & \multicolumn{1}{c}{$\mathbf{\%}$} \\
\hline $\begin{array}{l}\text { Penemuan } \\
\text { Kasus }\end{array}$ & Ya & 22 & 100 \\
\multicolumn{1}{c}{ Aktif } & Tidak & 0 & 0 \\
& Ya & 22 & 100 \\
$\quad$ Pasif & tidak & 0 & 0 \\
Pengobatan TB & Adekuat & 22 & 100 \\
& Tidak & 0 & 0 \\
Promkes & adekuat & & \\
& Promkes & 22 & 100 \\
& Tidak & 0 & 0 \\
Pemeriksaan & Promkes & & \\
Sputum & Baik & 18 & 81,8 \\
& Tidak baik & 4 & 18,2 \\
\hline
\end{tabular}

Tabel 3 menunjukan bahwa 22 (100\%) responden pemegang program TB melaksanakan program penemuan kasus secara aktif dan juga pasif dikuti pengobatan TB dan promkes 18(81,8\%) responden petugas laboratorium TB melaksanakan program pemeriksaan sputum dengan baik. Sedangkan 4(18,2) responden petugas laboratorium TB tidak baik melaksanakan program pemeriksan sputum.

\section{PEMBAHASAN}

\section{Penemuan Kasus}

Salah satu program pengendalian Tuberkulosis di puskesmas yang merupakan faktor penting dalam menentukan Case Detection Rate puskesmas adalah program penemuan kasus baik yang dilaksanakan secara aktif ataupun pasif. Hasil penelitian program penemuan kasus secara aktif dan pasif yang dilakukan di puskesmas di kota Ambon, diperoleh penemuan kasus yang dilakukan di 22 puskesmas secara aktif $(100 \%)$ dan penemuan kasus secara pasif (100\%). Dapat disimpulkan bahwa seluruh puskesmas di kota Ambon menjalankan program penemuan kasus dengan presentase $100 \%$ baik penemuan kasus secara aktif ataupun pasif. Walapun seluruh responden sudah melaksanakan penemuan kasus di semua puskesmas dengan baik namun sebagaian besar puskesmas di kota Ambon belum mencapai $70 \%$. 
Hasil penelitian Adi tama 2013 di puskesmas Boyolali menyebutkan pada pelaksanaan kegiatan P2TB di tiap-tiap Puskesmas di Kabupaten Boyolali, sekitar $34,50 \%$ Puskesmas melaksanakan active case finding, selebihnya melaksanakan atau melakukan passive promotive case finding. Strategi penemuan pasien TB adalah secara pasif, pemeriksaan terhadap kontak pasien dilakukan kepada keluarga dengan gejala sama. Penemuan aktif dianggap tidak efektif untuk biaya karena banyak memerlukan biaya(Aditama, Zulfikar., \& Baning, 2013).

Berdasarkan hasil wawancara mendalam diperoleh informasi bahwa kegiatan penemuan kasus yang dilakukan baik secara aktif yaitu ketuk pintu atau door to door dan pasif yaitu pasien datang ke puskesmas sudah di laksanakan dengan baik di 22 puskesmas di kota Ambon karena sudah terintegrasi dengan program PIS-PK dan program daerah binaan. Petugas yang melakukan kegiatan ini jug bukan hanya pemegang program TB tetapi juga di bantu dengan beberapa petugas darbin yang adad di puskesmas itu. Selain itu dana untuk kegiatan ini berasal dari dana bantuan oprasional kesehatan (BOK), sedangkan kegiatan monev dan lokmin dilakukan untuk mengetahui evaluasi di puskesmas mengenai kegiatan program penemuan kasus. Dalam pelaksanaan kegiataan penemuan kasus ini terdapat beberapa kendala yakni kurang berpatisipasi aktif masyarakat karena stigma masyarakat tentang penyakit TB ini merupakan suatu penyakit kutukan, suspek TB yang diberikan pot untuk tempat dahak tidak di kembalikan ke puskesmas adapun juga jika dikembalikan potnya juga berisi dahak yang kualitas kurang baik. Kendala lain yang ditemukan dalam wawancara mendalam ini yaitu SDM kurang karena ada beberapa puskesmas yang petugas program TB dan juga petugas laboratorium memiliki jabatan maupun tugas rangkap, selain itu juga kondisi demografi atau tempat tinggal masyarakat yang jauh, sulit dan susah di akses dengan kendaraan sehingga membutuhkan biaya tambahan.

\section{Pengobatan TB}

Pengobatan TB adalah salah satu upaya paling efisien untuk mencegah penyebaran lebih lanjut kuman TB. Salah satu tujuan pengobatan TB Mencegah terjadinya kematian oleh karena TB atau dampak buruk selanjutnya. Hasil penelitan sebagaimana dijabarkan dalam tabel 1.3 diketahui bahwa program pengobatan TB menunjukan bahwa 22 $(100 \%)$ responden pemegang program 
TB melaksanakan program pengobatan TB dengan pengobatan yang adekuat.

Hasil penelitian Noveyani di puskesmas Tanah Kalikedinding Surabaya tahun 2014 pelaksanaan pengobatan di puskesmas Tanah Kalikedinding kurang efektif dikarenakan terdapat pasien TB yang tidak mempunyai PMO, kurangnya kepatuhan dan juga kesadaran pasien dalam minum OAT secara teratur, serta perubahan jadwal kunjungan pada fase lanjutan menjadi $2 \times /$ bulan dan konsumsi obat anti tuberculosis pada fase lanjutan yang tidak setiap hari seperti fase intensif menyebabkan pasien lupa menelan obat. Selain itu petugas kesehatan kurang fokus, karena pemegang program TB juga beberapa program lain di puskesmas (Noveyani, 2014).

Melalui wawancara mendalam yang dilakukan peneliti terhadap responden diperoleh informasi bahwa pengobatan TB yang dilakukan di puskesmas tahun 2014 di kota Ambon sudah di lakukan oleh pemegang program dengan baik, dana maupun bahan untuk kegiatan pengobatan TB ini berasal dari Dinas. Obat Anti Tuberkulosis (OAT) yang di gunakan untuk pengobatan diperoleh secara gratis dipuskesmas, selain itu juga petugas pemegang program menentukan
Pengawas Minum Obat(PMO) dengan menunjuk orang yang paling terdekat dengan pasien atau pun keluarganya. Kalau istri yang sakit maka PMO nya suami begitupun sebaliknya. Petugas seringkali mengikatkan untuk meminum obat melalui media telekomunikasi seperti telepon dan pesan singkat, sesekali petugas langsung ke rumah pasien untuk memantau perkambangan pengobatan pasien. Lokmin dan monev dilakukan untuk mengetahui evaluasi pengobatan TB di puskesmas.

Untuk pelaksanaan pengobatan TB ini di peroleh beberapa kendala dari hasil yang didapat dari wawancara mendalam yakni stigma masyarakat tentang penyakit TB sebagai penyakit kutukan sehingga masyarakat atau pasien malu untuk berobat. Jarak rumah pasien deng puskesmas yang jauh mengakibatkan masyarakat malas untuk berobat atau datan ke puskesmas, selain itu juga pasien yang sudah minum obat selama 2 bulan dan merasa nyaman kemudian tidak melanjutkan minum lagi. Kendala yang berikut yakni pasien yang berobat di puskesmas pindah tempat tinggal dan tidak memberitahu ke petugas. Berobat ke puskesmas lain atau fasilitas kesehatan yang ada ditempat lain lain seperti RS, dokter praktek dll juga merupakan 
kelemahan maupun kendala dalam pengobatan TB.

\section{Promkes TB}

Promosi kesehatan dapat berperan dalam penanggulangan TB sebagai berikut yaitu menjadi panutan untuk tidak menciptakan stigma ataupun diskriminasi terkait TB, serta Mendorong pasien TB untuk bisa menjalankan pengobatan secara tuntas, dan Membantu menyebarluaskan informasi tentang TB dan PHBS, kemudian bisa Mendorong masyarakat agar segera memeriksakan diri ke layanan kesehatan TB yang baik dan berkualitas. Hasil penelitian sebagaimana dijabarkan dalam tabel 5.15 menunjukan bahwa diketahui $22(100 \%)$ responden pemegang program TB melaksanakan program promosi kesehatan.

Berdasarkan penelitian yang telah dilakukan Mansur (2015) terdapat angka penemuan kasus TB paru dan angka kesembuhan yang masih belum juga smapai atau mencapai target nasional yang telah ditetapkan. Hal ini dikarenakan petugas TB paru tidak selalu melakukan penyuluhan kepada masyarakat mengenai penyakit TB paru (Mansur, Khadijah \& Rusmalawaty, 2015). Hasil yang disampaikan oleh Noveyani tahun 2014 pada penelitiannya di puskesmas tanah
Kalikedinding Surabaya bahwa target CDR yang mencapai target disebabkan karena penyuluhan dilakukan oleh petugas secara rutin saat pasien berobat di puskesmas dan juga media-media informasi pertama kali didapat oleh hampir seluruh $(84,4 \%)$ responden pasien yakni dari petugas kesehatan (Noveyani, 2014).

Berdasarkan hasil wawancara mendalam terhdap responden diperoleh informasi yaitu bahwa promosi kesehatan yang dilakukan di puskesmas kota Ambon sudah berjalan dengan baik. Untuk kegiatan ini terintegrasi dengan PIS-PK dan Darbin untuk di luar puskesmas, selain itu juga dilaksaakan di tempattempat ibadah maupun di sekolah. kegiatan ini juga dilaksanakan hampir setiap bulan dengn frekuensi yang berbeda beda tiap puskesmasnya dengn dana yang bersasal dari BOK. Sarana prasrana untuk program penemuan kasus ini juga sudah terpenuhi dan tercukupi pada semua puskesmas di kota Ambon. Petugas pemegang program TB merupakan orang yang bertanggung jawab terhdap kegiatan ini, selain itu juga dibantu dengan petugas promkes. Adapun untuk evaluasinya berupa lokmin dan monev. 
Program promosi kesehatan yang terdapat di puskesmas Kota Ambon berdasarkan wawancara mendalam ditemui beberapa kendala atau kelemahan yakni masyrakat yang belum memahami penyakit TB secara baik dan kesibukan pekerjaan masyarakat sehingga mereka tidak menghadiri kegiatan yang di lakukan di puskesmas ataupun di tempat-tempat lain Pemeriksaan sputum atau dahak selain berfungsi untuk menegakkan diagnosis, juga agar bisa menilai atau mengukur keberhasilan pengobatan dan menentukan potensi penularan dan menilai keberhasilan pengobatan. hasil penelitian mengenai program pemeriksaan dahak atau sputum puskesmas di kota Ambon diperoleh bahwa 18(81,8\%) responden petugas laboratorium TB melaksanakan program pemeriksaan sputum dengan baik, Sedangkan $4(18,2)$ responden petugas laboratorium TB tidak baik melaksanakan program pemeriksan sputum.

Hasil penelitian Noveyani (2014) menjelaskan bahwa CDR Puskesmas Tanah Kalikedinding memenuhi target nasional $\geq 70 \%$ Sedangkan SR belum mencapai target $\geq 85 \%$. Hal ini di karenakan pada hasil penilitian yang dilakukan menurut responden pemegang program TB bahwa seluruh (100\%) pasien diperiksa menggunakan dan mengiuti alur diagnosis sesuai yang dengan pedoman pengendalian TB dari Depkes RI kecuali pemeriksaan rontgen, disebabkan karena tidak tersedianya alat untuk rontgen dan juga teknisinya kemudian keterangan petugas laboratorium, seluruh (100\%) pasien TB diperiksa dahaknya mengikuti maupun menggunakan alur pemeriksaan dahak mikroskopis yang dilakukan sesuai pedoman pengendalian TB Depkes RI (Noveyani, 2014).

Menurut penelitian Mansur tahun 2015, menunjukkan angka kesembuhan penderita TB belum sebesar 85\% yang mana belum mencapai target yang ditetapkan. Hal ini disebabkan karena puskesmas desa Lalang dalam pelaksanaan penanggulangan TB paru hanya sampai melakukan fiksasi slide saja, yang melakukan pewarnaan dan pemeriksaan mikroskopis adalah Puskesmas Helvetia sebagai PRM. Pemeriksaan sputum dilaksanakan dengan cara menampung sputum/dahak sesuai dengan pedoman SPS (sewaktupagi-sewaktu), namun masih terdapat hambatan dari pasien yaitu kurangnya pengetahuan pasien dalam menampung dahak yang benar agar ketika dahak di periksa secara mikroskopis maka hasil 
yang didapat seharusnya BTA positif (Mansur, Khadijah \& Rusmalawaty, 2015).

Penelitian Aditama tahun 2013 mengatakan bahwa identifikasi kasus dilakukan dengan cara pemeriksaan sputum atau dahak olah petugas di puskesmas. Setiap puskesmas di Kabupaten Boyolali telah memiliki laboratorium dan jug mampu melakukan pemeriksaan sediaan sputum atau dahak penderita TB namun pencapaian program P2TB paru Kabupaten Boyolali tahun 2009 masih jauh dari target yang telah ditetapkan (Aditama, Zulfikar., \&Baning, 2013).

Berdasarkan wawancara mendalam yang dilakukan peneliti diperoleh informasi bahwa Untuk pemeriksaan sputum yang dilakukan di puskesmas di kota Ambon oleh petugas laboratorium puskesmas sudah di lakukan dengan baik hal ini juga bisa dilihat dengan sebagian besar 18,8\% responden melakukan pemeriksaan dengan baik. Pemeriksaan sputum yang dilakukan sudah bukan dengn SewaktuPagi-Sewaktu tapi S-P saja, kemudian semua dana untuk menunjang program ini berasal dari Dinas Kesehatan Kota. alat dan bahan untuk program pemeriksan sputum sudah terpenuhi tapi ruangan. Slide pemeriksaan pasien dikirim ke wasor untuk melakukan uji silang agar bisa menentukan apakah ada kesalahan pemeriksaan (error rate). Adapun kelemahan atau kendala yang di peroleh dalam wawancara mendalam ini yaitu laboratorium yang kecil dan harusnya laboratorium untuk TB dipisahkan sendiri. Sputum maupun dahak yang di berikan petugas pemegang program kepada petugas laboratorium kualitasnya kurang baik sehingga pemeriksaan tidak bisa dilakukan.

\section{KESIMPULAN}

Program penemuan kasus secara aktif dan pasif sudah dilakukan 100\%, Program pengobataan TB yang adekuat sudah dilakukan 100\%, Program promosi kesehatan sudah dilakukan 100\% diseluruh puskesmas di kota Ambon, walaupun seluruh responden sudah melaksanakan program-program ini tapi sebagian besar CDR puskesmas di kota Ambon masih di bawah target $\geq 70 \%$ hal ini di karenakan pemahaman masyarakat tentang TB masih kurang sehingga partisipasi masyarakat kurang.

\section{SARAN}

Menjalin kerja sama lintas bidang dan sektor dalam melakukan kegiatan pada masing-masing program. Adanya upaya penggerakan partisipasi aktif masyarakat 
dalam program-program pengendalian Tuberkulosis. Adanya perbaikan ruangan laboratorium yang lebih memadai yakni luas dan memiliki ruangan tersendiri untuk pemeriksaan sputum. Perbaikan kualitas dahak dengan memberikan memberikan pelatihan kepada pasien TB paru bagaimana cara mengeluarkan sputum yang benar.

\section{REFERENSI}

Aditama, W., Zulfikar., \& Baning R. (2013). Evaluasi program penanggulangan tuberkulosis paru di kabupaten Boyolali. Jurnal Kesehatan Masyarakat Nasional Vol. 7, No. 6 : 243-250.

Dinkes Kota Ambon. (2017). Profil Data Kesehatan Kota Ambon Tabun 2017. Ambon. Dinas Kesehatan Kota Ambon.

Dinkes Provmal. (2016). Profil Dinas Kesehatan Kesehatan Provinsi Maluku. Ambon: Dinas Kesehatan Provinsi Maluku.

Dwijowijoto, R. N. (2003). Kebijakan Publik (Formulasi, Implementasi, dan Evaluasi). Jakarta: Penerbit PT Elex Media Komputindo.

Firdaufan., Santoso., Hartanto R., Hendratno., Sumardiyono., . . .., Syahril M. (2009). Evaluasi Program Pengendalian Tuberkulosis Dengan Strategi DOTS di Eks Karesidenan Surakarta. Jurnal Kedokteran Indonesia. Vol. 1, No. $2: 199-208$.

Kemenkes RI . (2016). Penanggulangan Tuberkulosis. Jakarta: Kementrian Kesehatan Republik Indonesia Permenkes RI.No.67/Menkes/2016. RI.
Kemenkes RI. (2017). . Profil Kesehatan Indonesia 2016. Jakarta : Kementrian Kesehatan Republik Indonesia.

Kemenkes. (2011). Strategi Nasional Pengendalian TB DI Indonesia 20102014. Jakarta: Kementrian Kesehatan Republik Indonesia Direktorat Jenderal Pengendalian Penyakit Dan Penyehatan Lingkungan.

Mansur M., Khadijah S., \& Rusmalawaty. (2015). Analisis Penatalaksanaan Program Penanggulangan Tuberkulosis Paru Dengan Strategi DOTS Di Puskesmas Desa Lalang Kecamatan Medan Sunggal Tahun 2015. Lingkungan dan Kesehatan Kerja. Vol 4. N0. 2.

Murti B.(1995) Prinsip dan metode riset epidemiologi. Yogyakarta: Gadjah Mada University Press.

Murti, B. (2010). Desain dan Ukuran Sampel dalam Penelitian Kesehatan : Edisi ke-. 2. Yogyakarta : Gadjah Mada University Press.

Noveyani, A. E., \& Martini, S. (2014). Evaluasi Program Pengendalian Tuberkulosis Paru Dengan Strategi DOTS di Puskesmas Tanah Kalikedinding Surabaya. Jurnal Berkala Epidemiologi. Vol. 2, No. 2 : 251-262.

Saryono., Anggraeni, M, D. (2013). Metodologi Penelitian Kualitatif dan Kuantitatif dalam Bidang Kesehatan. Yogyakarta: Nuha Medika.

WHO. (2016)Global Tuberculosis Control WHO Report. Jenewa: World Health Organization.

Brannen Y. (2005).Memadu Metode Penelitian Kualitatif dan Kuantitatif. Yogyakarta: Pustaka Pelajar. 